\title{
Optimalisasi Potensi Wisata dan Pengurangan Resiko Bencana di Desa Pentadio Barat untuk Mendukung Pembangunan Berkelanjutan Daerah Dataran Danau Limboto, Kabupaten Gorontalo
}

\author{
Optimizing Tourism Potential and Reducing Disaster Risk in West Pentadio Village to Support \\ Sustainable Development of the Limboto Lake Plain Area, Gorontalo Regency
}

\author{
Intan Noviantari Manyoe ${ }^{{ }^{*}}$, Ronal Hutagalung ${ }^{1}$ \\ ${ }^{1}$ Fakultas Matematika dan Ilmu Pengetahuan Alam, Universitas Negeri Gorontalo \\ *intan.manyoe@ung.ac.id
}

\begin{abstract}
ABSTRAK
Berbah adalah sebuah kecamatan di Kabupaten Sleman, Provinsi Daerah Istimewa Yogyakarta, Indonesia. Dalam hal kemajuan pendidikan usia dini terdapat beberapa taman kanak-kanak (TK) di kecamatan berbah diantaranya TK PANTI DEWI. Permasalahan yang dihadapi oleh mitra yaitu penilaian rapor hingga saat ini masih menggunakan teknik konvensional ditulis penilaian deskriptif secara manual sehingga membutuhkan waktu yang cukup tinggi dalam prosesnya. Hal lain adalah gaya penulisan yang berbeda-beda jika ditulis manual dan beberapa masalah human error baik dari sisi orang tua ataupun guru-guru. Solusi yang ditawarkan tersedianya sebuah website rapor online yang dapat dijadikan sebagai media penunjang dalam penilaian rapor, serta pendampingan pelatihan pengoperasian menggunakan komputer untuk meningkatkan kemampuan guru-guru TK Panti Dewi. Dalam kegiatan ini dilakukan juga pendampingan terhadap orang tua anak didik dalam penerimaan rapor menggunakan website. Dengan adanya program ini pada akhir pelaksanaan kegiatan mitra mampu meningkatkan efisiensi waktu penilaian rapor penulisan rapor hasil ajar menjadi lebih efektif dan efisien bahkan memberikan invoasi baru bagi orang tua jaman milenial yang anak-anaknya sekolah TK di Panti Dewi saat ini yakni dapat menerima rapor anak dalam bentuk softcopy secara online serta dapat unduh sendiri melalui gadget yang dimiliki.
\end{abstract}

Kata kunci — berbah, rapor onine, website, TK

\begin{abstract}
Berbah is a sub-district in Sleman Regency, Yogyakarta Special Region Province, Indonesia. In terms of progress in early childhood education, there are several kindergartens (TK) in the Berbah sub-district, including the DEWI PANTI TK. The problem faced by partners is that the assessment of report cards until now still uses conventional techniques, written descriptive assessments manually, so that it requires a fairly high amount of time in the process. Another thing is the different writing styles if written manually and some human error problems from both the parents and teachers side. The solution offered is the availability of an online report card website that can be used as a supporting medium in assessing report cards, as well as providing operational training assistance using computers to improve the abilities of Panti Dewi Kindergarten teachers. In this activity, assistance was also carried out for parents of students in receiving report cards using the website. With this program at the end of the implementation of partner activities, it is able to improve the time efficiency of assessing report cards writing teaching results to be more effective and efficient and even providing new innovations for millennial parents whose children are in kindergarten at Panti Dewi at this time, namely being able to receive children's report cards in in the form of online softcopy and can be downloaded by yourself through the gadget you have.
\end{abstract}

Keywords - berbah, online report card, website, kindergarten 


\section{Pendahuluan}

Potensi wisata mampu menjadi leading sector perekonomian suatu daerah (Pitana, 1999 [2]). Pengembangan desa wisata mampu memberi manfaat bagi peningkatan pendapatan masyarakat melalui penciptaan lapangan kerja baru, industri-industri kreatif, transportasi, dan penginapan (Andriyani, Martono, and Muhamad 2017; Zulfianita and Setiawan 2015; Septian et.al, 2019 [1] ). Desa wisata lahir dari konsepkonsep wisata unggulan yang ada dalam suatu desa. Selain itu, poin penting dalam pengembangan desa wisata yang harus senantiasa diperhatikan adalah perlindungan kepada wisatawan yang berkunjung ke desa wisata. Sehingga upaya mitigasi bencana penting untuk dilakukan dalam pengembangan desa wisata.

Desa Pentadio Barat secara administrasi berada pada Kecamatan Telaga Biru, Kabupaten Gorontalo, Provinsi Gorontalo. Desa Pentadio Barat berbatasan dengan Danau Limboto. Danau Limboto memiliki kekayaan geologi, kekayaan biologi dan kekayaan budaya. Sehingga memiliki potensi yang sangat besar bila dikembangkan menjadi wisata. Selain Danau Limboto, Desa Pentadio Barat memiliki potensi pengembangan wisata terpadu. Optimalisasi potensi wisata di Desa Pentadio Barat juga harus dibarengi dengan upaya pengurangan risiko bencana sebagai bentuk langkah mitigasi untuk perlindungan warga dan wisatawan.

Upaya optimalisasi potensi wisata dan pengurangan risiko bencana dapat membantu pemerintah dan masyarakat dalam pengembangan wisata desa serta dapat mengambil tindakan yang tepat agar optimalisasi wisata dan pengurangan risiko bencana dapat mendukung pembangunan berkelanjutan di pesisir Danau Limboto. Program KKN Tematik menjadi program yang penting agar rencana optimalisasi potensi wisata dan pengurangan risiko bencana dapat di wujudkan di Pentadio Barat karena terjalinnya kerja sama antar stakeholder yaitu pemerintah Kabupaten Gorontalo, masyarakat, dan perguruan tinggi khususnya Universitas Negeri Gorontalo.

Metode yang diterapkan dalam menuju tercapainya program optimalisasi potensi wisata dan pengurangan risiko bencana yaitu diawali dengan melakukan survei potensi wisata dan bencana. Selanjutnya pembuatan papan informasi wisata, papan informasi bencana, modul wisata dan modul bencana untuk Desa Pentadio Barat. Langkah berikutnya mengenalkan program optimalisasi potensi wisata dan pengurangan risiko bencana untuk mendukung pembangunan berkelanjutan melalui sosialisasi. Aspek penting yang menjadi penekanan adalah peningkatan pengetahuan masyarakat terkait optimalisasi wisata, pengurangan risiko bencana untuk mendukung pembangunan berkelanjutan. Aspek penting lainnya adalah mendorong masyarakat untuk memahami dan melakukan aksi, sehingga masyarakat memperoleh sebanyak mungkin pengetahuan dan pengalaman dalam program optimalisasi wisata dan pengurangan risiko bencana. Aksi yang dilakukan setelah sosialisasi terkait optimalisasi potensi wisata adalah pembersihan dan penataan lokasi wisata. Aksi yang dilakukan setelah sosialisasi terkait program pengurangan risiko bencana adalah pembersihan drainase dan lingkungan desa serta penghijauan dan pembuatan biopori untuk pengurangan risiko bencana. Pembersihan dan penghijauan juga dilakukan di daerah bantaran sungai. Seluruh program kegiatan dan luaran kemudian didokumentasi pada website dan dalam bentuk video.

\section{Target dan Luaran}

Target dari pelaksanaan program KKN Tematik dengan judul "Optimalisasi Potensi Wisata dan Pengurangan Risiko Bencana di Desa Pentadio Barat untuk Mendukung Pembangunan Berkelanjutan Daerah Dataran Danau Limboto" adalah untuk :

a. Peningkatan pengetahuan masyarakat terkait optimalisasi wisata untuk mendukung pembangunan berkelanjutan.

b. Peningkatan pengetahuan masyarakat terkait pengurangan risiko bencana untuk mendukung pembangunan berkelanjutan.

c. Peningkatan partisipasi masyarakat terkait optimalisasi potensi wisata melalui aksi pembersihan dan penataan lokasi wisata.

d. Peningkatan partisipasi masyarakat terkait program pengurangan risiko bencana melalui aksi penghijauan dan pembuatan biopori. 
Luaran dari pelaksanaan program ini adalah Peta Administrasi Desa, Peta Situs Wisata, Peta Zona Rawan Bencana Banjir , Papan Informasi Wisata, Papan Informasi Bencana, Modul Wisata, Modul Bencana, Buku Sekolah Geotermal, Website potensi wisata dan potensi bencana, serta jurnal ilmiah.

\section{Metodologi}

Metode pelaksanaan kegiatan KKN Tematik dengan judul "Optimalisasi Potensi Wisata dan Pengurangan Risiko Bencana di Desa Pentadio Barat untuk Mendukung Pembangunan Berkelanjutan Daerah Dataran Danau Limboto" meliput :

\subsection{Persiapan dan Pembekalan}

\subsubsection{Mekanisme pelaksanaan kegiatan KKN Tematik}

Mekanisme pelaksanaan kegiatan KKN Tematik meliputi tahapan-tahapan: a) Penyiapan lokasi KKN Tematik; b) Koordinasi dengan dinas/pemerintah setempat; c) Perekrutan mahasiswa peserta koordinasi dengan LPPMUNG; d) Pembekalan (Coaching) dan pengasuransian mahasiswa.

\subsubsection{Materi persiapan dan pembekalan KKN Tematik}

Materi persiapan dan pembekalan bagi mahasiswa peserta kegiatan KKN Tematik dilakukan oleh LP2M dan Dosen Pembimbing Lapangan (DPL) yang meliputi materi yang diberikan oleh LP2M Universitas Negeri Gorontalo dan materi yang diberikan oleh Dosen Pembimbing Lapangan (DPL).

\subsection{Pelaksanaan Program}

Pada pelaksanaan program KKN Tematik dengan judul "Optimalisasi Potensi Wisata dan Pengurangan Risiko Bencana di Desa Pentadio Barat untuk Mendukung Pembangunan Berkelanjutan Daerah Dataran Danau Limboto" dibagi menjadi 2 tipe program yaitu Program Inti dan Program Tambahan. Rincian program tersebut dapat dilihat pada tabel 1 di bawah ini.

Tabel 1. Program dan Metode Pelaksanaan Program KKN Tematik

\begin{tabular}{|c|c|c|c|c|c|}
\hline No. & Program & Sub & Program & Metode & Kelompok Sasaran \\
\hline 1 & Survei & $\begin{array}{l}\text { a) } \\
\text { b) } \\
\text { c) }\end{array}$ & $\begin{array}{l}\text { Survei batas desa } \\
\text { Survei potensi wisata } \\
\text { Survei potensi bencana }\end{array}$ & $\begin{array}{l}\text { Observasi } \\
\text { lapangan }\end{array}$ & $\begin{array}{l}\text { Aparat desa dan karang } \\
\text { taruna }\end{array}$ \\
\hline 2 & Pemetaan & $\begin{array}{l}\text { a) } \\
\text { b) } \\
\text { c) }\end{array}$ & $\begin{array}{l}\text { Pemetaan administrasi desa } \\
\text { Pemetaan situs wisata } \\
\text { Pemetaan zona rawan bencana }\end{array}$ & Pelatihan & $\begin{array}{l}\text { Aparat desa dan karang } \\
\text { taruna }\end{array}$ \\
\hline 3 & $\begin{array}{l}\text { Pembuatan } \\
\text { papan } \\
\text { informasi }\end{array}$ & $\begin{array}{l}\text { a) } \\
\text { b) }\end{array}$ & $\begin{array}{l}\text { Pembuatan papan informasi wisata } \\
\text { Pembuatan papan informasi bencana }\end{array}$ & $\begin{array}{l}\text { Perancangan dan } \\
\text { Pelatihan }\end{array}$ & $\begin{array}{l}\text { Aparat desa dan karang } \\
\text { taruna }\end{array}$ \\
\hline 4 & $\begin{array}{l}\text { Pembuatan } \\
\text { modul }\end{array}$ & $\begin{array}{l}\text { a) } \\
\text { b) }\end{array}$ & $\begin{array}{l}\text { Pembuatan modul wisata } \\
\text { Pembuatan modul pengurangan risiko } \\
\text { bencana }\end{array}$ & $\begin{array}{l}\text { Perancangan dan } \\
\text { Pelatihan }\end{array}$ & $\begin{array}{l}\text { Aparat desa dan karang } \\
\text { taruna }\end{array}$ \\
\hline 5 & Sosialisasi & $\begin{array}{l}\text { a) } \\
\text { b) } \\
\text { c) }\end{array}$ & $\begin{array}{l}\text { Sosialisasi SDGs } \\
\text { Sosialisasi optimalisasi potensi wisata } \\
\text { Sosialisasi pengurangan risiko bencana }\end{array}$ & Sosialisasi & $\begin{array}{l}\text { Aparat desa, karang taruna } \\
\text { dan masyarakat desa }\end{array}$ \\
\hline 6 & $\begin{array}{l}\text { Optimalisasi } \\
\text { potensi } \\
\text { wisata }\end{array}$ & $\begin{array}{l}\text { a) } \\
\text { b) }\end{array}$ & $\begin{array}{l}\text { Pembersihan lokasi wisata } \\
\text { Penataan lokasi wisata }\end{array}$ & Pelatihan & $\begin{array}{l}\text { Aparat desa, karang taruna } \\
\text { dan masyarakat desa }\end{array}$ \\
\hline 7 & $\begin{array}{l}\text { Pengurangan } \\
\text { risiko } \\
\text { bencana }\end{array}$ & a) & $\begin{array}{l}\text { Pembersihan drainase dan lingkungan } \\
\text { desa } \\
\text { Penghijauan dan pembuatan biopori }\end{array}$ & Pelatihan & $\begin{array}{l}\text { Aparat desa, karang taruna } \\
\text { dan masyarakat desa }\end{array}$ \\
\hline 8 & Pendidikan & a) & Sekolah Geotermal & Pelatihan & Anak-anak Sekolah Dasar \\
\hline 9 & $\begin{array}{l}\text { Pembuatan } \\
\text { media } \\
\text { informasi }\end{array}$ & & $\begin{array}{l}\text { Pembuatan website } \\
\text { Pembuatan video }\end{array}$ & Pelatihan & $\begin{array}{l}\text { Aparat Desa dan karang } \\
\text { taruna }\end{array}$ \\
\hline 10 & $\begin{array}{l}\text { Program-prog } \\
\text { dan kegiatan } 1\end{array}$ & $\begin{array}{l}\text { am ta } \\
\text { ari ke }\end{array}$ & $\begin{array}{l}\text { ambahan: membersihkan masjid, tenaga } \\
\text { merdekaan berupa pertunjukan kesenian }\end{array}$ & $\begin{array}{l}\text { Intu mengajar di TP } \\
\text { lan lomba olahraga }\end{array}$ & penyemprotan desinfektan \\
\hline
\end{tabular}




\section{Pembahasan}

Hasil yang dicapai selama pelaksanaan program KKN Tematik Periode I 2020, di Desa Pentadio Barat yang terdiri dari 9 program unggulan, 11 sub program unggulan dan 3 program tambahan. Adapun hasil dari pelaksanaan program-program tersebut, dijelaskan sebagai berikut:

\subsection{Survei Potensi Wisata dan Potensi Bencana}

Hasil yang diperoleh pada program ini adalah tersedianya data hasil survei. Program ini terdiri dari tiga sub program yaitu (1) survei batas desa (2) survei potensi wisata dan (3) survei potensi bencana. Deskripsi masing-masing kegiatan tersebut adalah sebagai berikut:

\subsubsection{Survei batas desa;}

Kegiatan ini dimaksudkan untuk melakukan kunjungan ke batas desa dan batas dusun. Data ini sebagai data dasar potensi wisata dan potensi bencana. Data yang dikumpulkan terdiri dari:

a. Data koordinat batas desa dan dusun;

b. Data koordinat pemukiman;

c. Data koordinat fasilitas umum.

\subsubsection{Potensi wisata;}

Kegiatan ini dimaksudkan untuk melakukan kunjungan ke lokasi-lokasi yang memiliki potensi wisata. Data yang dikumpulkan terdiri dari:

a. Data koordinat potensi wisata;

b. Data jenis wisata;

c. Data koordinat pemasangan papan informasi wisata

\subsubsection{Survei potensi bencana;}

Kegiatan ini dimaksudkan untuk melakukan kunjungan ke lokasi-lokasi yang memiliki potensi bencana. Data yang dikumpulkan terdiri dari:

a. Data koordinat potensi bencana;

b. Data jenis bencana;

c. Data koordinat pemasangan papan informasi bencana
Pengambilan data dilakukan dengan menggunakan GPS receiver, kamera smartphone, termometer infrared, dan alat tulis geologi.

\subsection{Pemetaan Administrasi Desa, Situs Wisata dan Zona Rawan Bencana}

Kegiatan ini adalah kegiatan pemetaan administrasi desa, pemetaan potensi wisata dan pemetaan potensi bencana. Peta administrasi desa memuat data pemukiman, sungai, jalan, batas desa, batas dusun, kantor desa, taman makam pahlawan serta fasilitas umum yang terdapat di desa meliputi sekolah dan masjid.
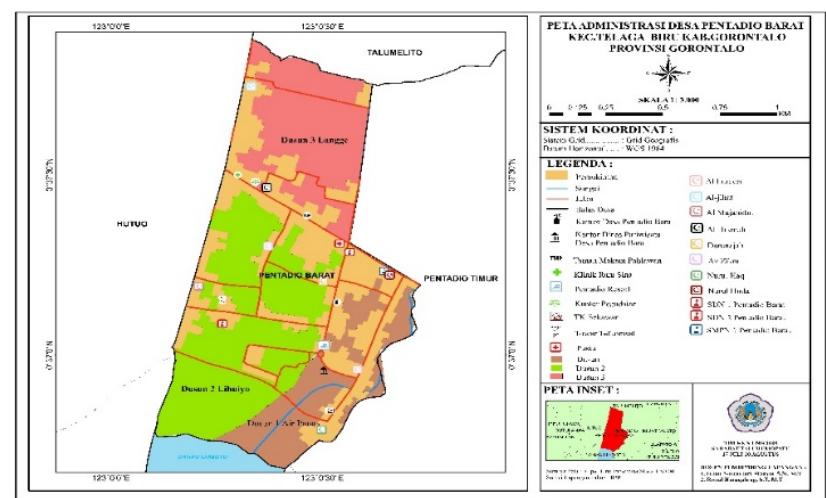

Gambar 1. Peta Administrasi Desa Pentadio Barat

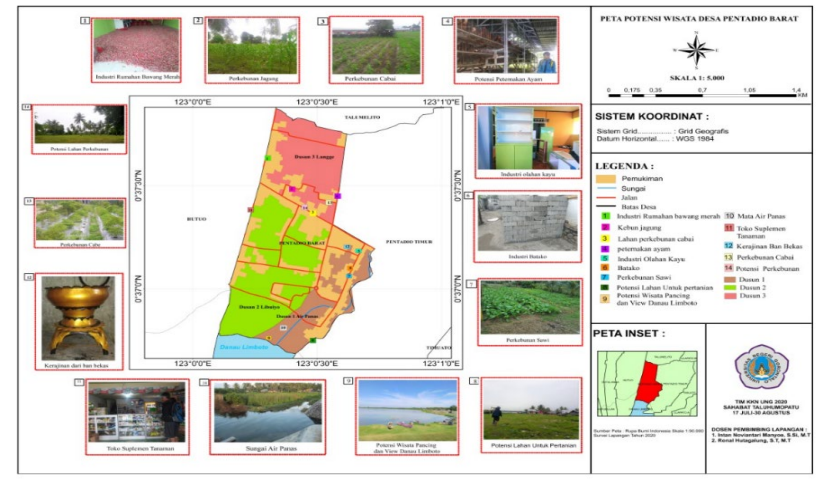

Gambar 2. Peta Potensi Wisata Desa Pentadio Barat

Peta potensi wisata Peta potensi wisata Desa Pentadio Barat memuat data situs wisata alam seperti mata air panas, sungai air panas, Danau Limboto, agrowisata dan produk kreatif warga desa yang menunjang wisata desa seperti kerajinan ban bekas. 
Peta potensi bencana Desa Pentadio Barat memuat data zona rawan bencana banjir. Zona rawan bencana terbagi atas tiga yaitu zona rawan, zona sedang dan zona aman. Zona rawan adalah daerah pesisir Danau Limboto dan daerah di sekitar sungai.

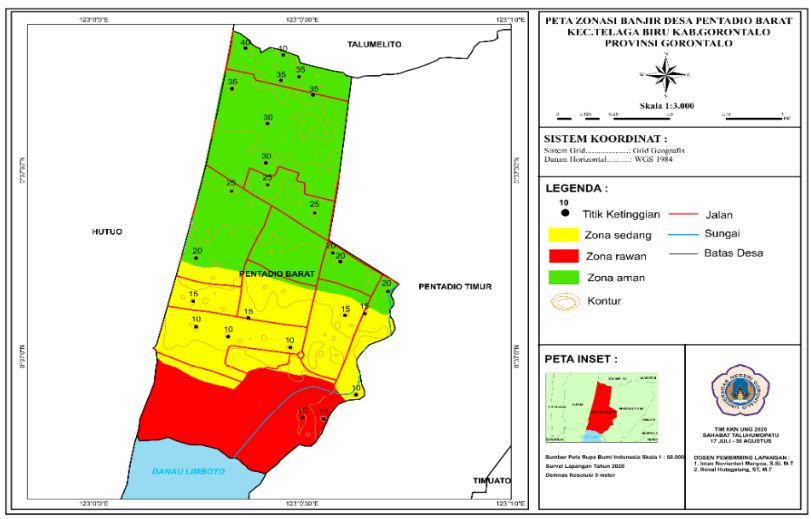

Gambar 3. Peta Zonasi Banjir Desa Pentadio Barat

\subsection{Pembuatan Papan Informasi Wisata dan Pengurangan Risiko Bencana}

Kegiatan ini adalah kegiatan pembuatan papan informasi wisata dan papan informasi pengurangan risiko bencana. Papan informasi wisata berisi potensi-potensi wisata yang ada di desa berdasarkan hasil survei dan pemetaan sedangkan papan informasi pengurangan risiko bencana berisi informasi dan langkah mitigasi bencana banjir.

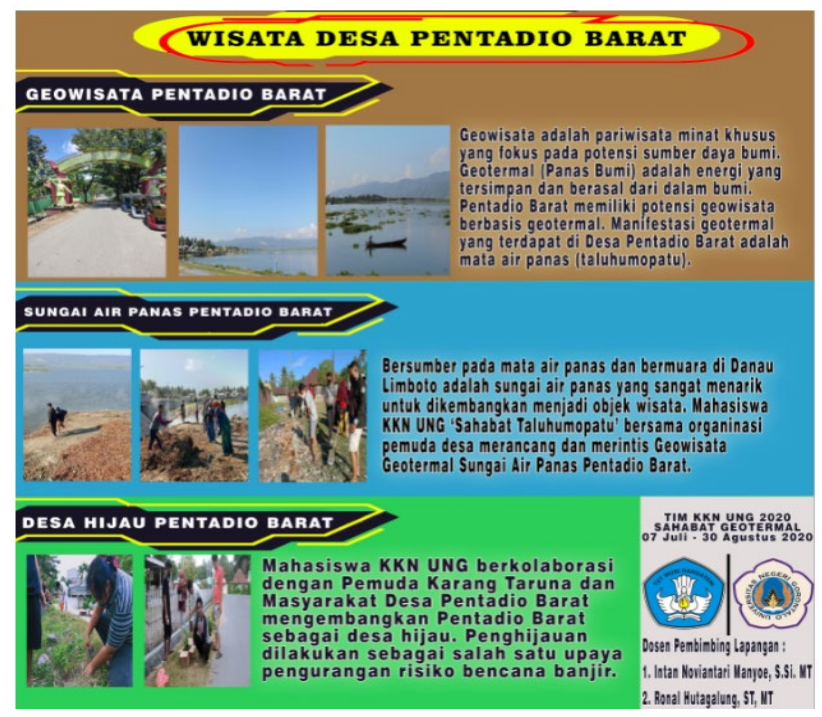

Gambar 4. Papan Informasi Wisata Desa Pentadio Barat

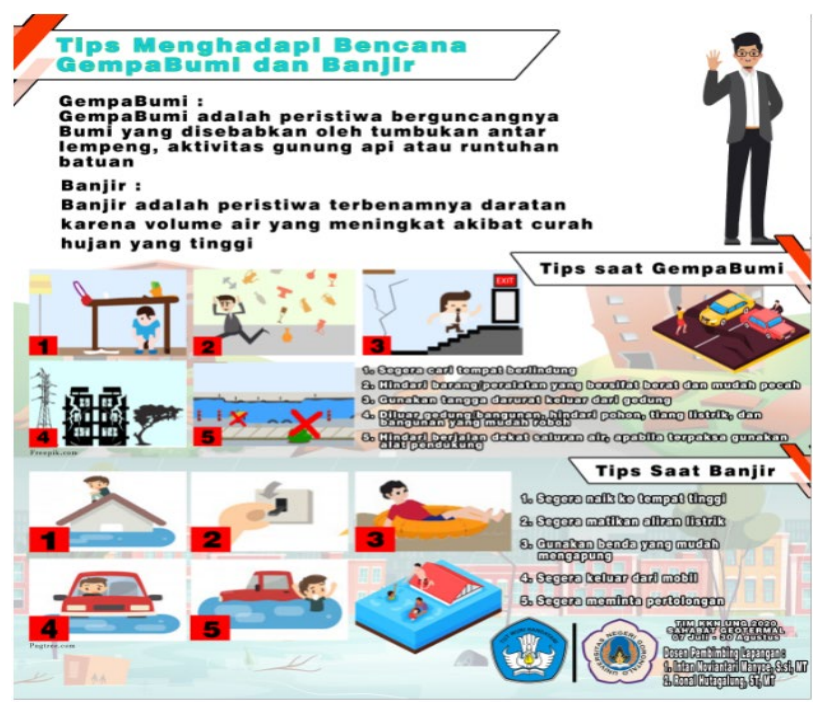

Gambar 5. Papan Informasi Bencana Desa Pentadio Barat

Papan informasi wisata Pentadio Barat berisi potensi wisata sungai air panas dan desa hijau. Papan informasi bencana Pentadio Barat berisi informasi bencana desa dan langkahlangkah mitigasi bencana. Pemasangan papan informasi dilakukan bersama karang taruna di sekitar lokasi wisata dan zona rawan bencana di desa.

\subsection{Pembuatan Modul Wisata dan Pengurangan Risiko Bencana}

Kegiatan ini adalah kegiatan pembuatan modul wisata berupa modul wisata geotermal Pentadio Barat. Modul pengurangan risiko bencana berupa modul pengurangan risiko banjir Desa Pentadio Barat.

Modul berisi penjelasan wisata dan bencana yang ada di Pentadio Barat. Dalam modul juga terdapat rancangan wisata untuk pengembangan wisata desa ke depan. Modul bencana berisi penjelasan mitigasi sebelum, saat dan setelah terjadi banjir.

\subsection{Sosialisasi SDGs, Optimalisasi Potensi Wisata dan Pengurangan Risiko Bencana}

Metode pelaksanaannya berupa sosialisasi SDGs, optimalisasi potensi wisata dan pengurangan risiko bencana. Sosialisasi optimalisasi potensi wisata difokuskan pada optimalisasi potensi wisata geotermal Pentadio Barat. Pengurangan risiko bencana difokuskan 
pada sosialisasi pengurangan risiko bencana banjir.

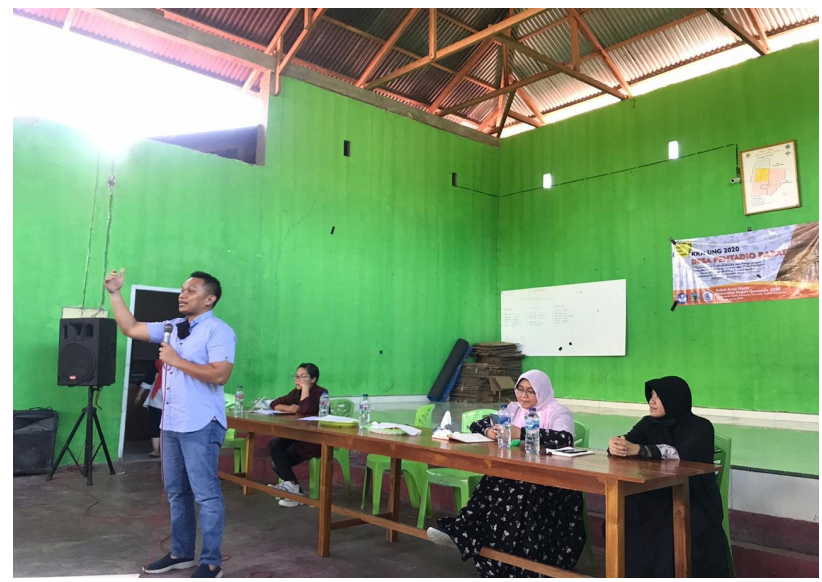

Gambar 6. Sosialisasi di Desa Pentadio Barat

Sosialisasi diikuti oleh aparat, organisasi karang taruna dan masyarakat desa. Sosialisasi di Desa Pentadio Barat dilaksanakan pada tanggal 5 Agustus 2020. Apresiasi yang sangat besar dari masyarakat desa dalam hal optimalisasi wisata sungai air panas karena potensi geotermal/ panas bumi di Pentadio Barat selama ini dikelola oleh Dinas Pariwisata Kabupaten Gorontalo.

\subsection{Program Optimalisasi Potensi Wisata}

Setelah survei, pemetaan, pembuatan papan informasi, modul, dan sosialisasi, selanjutnya dilakukan program pembersihan dan penataan lokasi wisata yaitu di pesisir Danau Limboto dan di lokasi geotermal sebagai bentuk aksi program optimalisasi potensi wisata.

Pembersihan dan penataan lokasi geotermal di Pentadio Barat dilakukan pada titik mata air panas dan pada sungai air panas. Dua potensi wisata ini belum dikelola oleh masyarakat maupun dinas pariwisata. Proses pelaksanaan bersih lokasi geotermal dan penataan lokasi dilakukan bersama dengan organisasi pemuda Desa Pentadio Barat. Wisata sungai air panas selanjutnya akan dikelola oleh BUMDES Pentadio Barat.

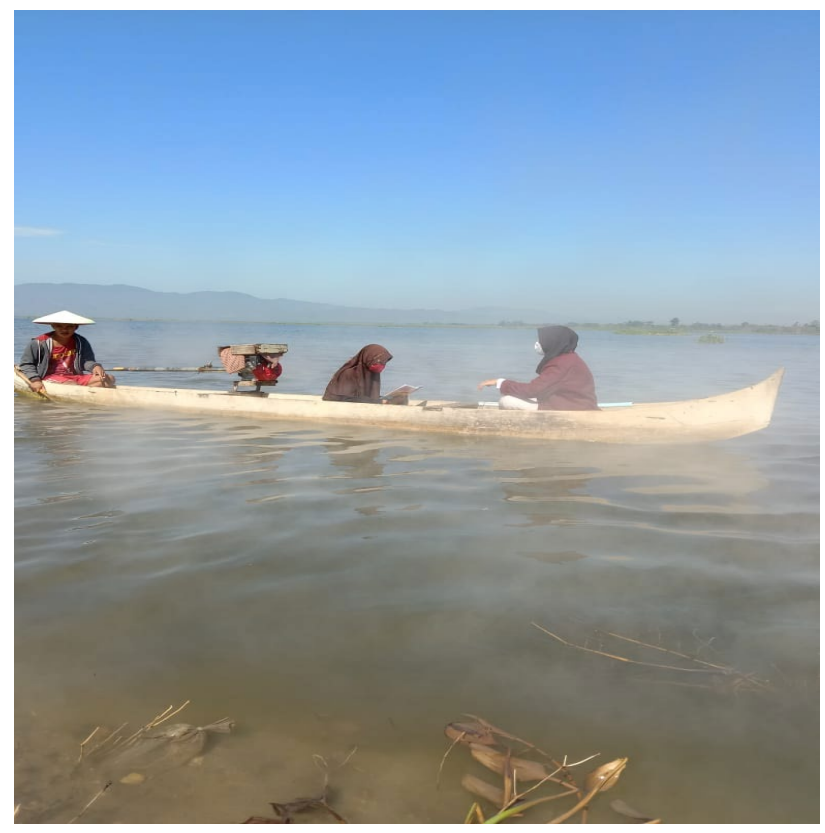

Gambar 7. Geowisata Sungai Air Panas di Desa Pentadio Barat

\subsection{Program Pengurangan Risiko Bencana}

Setelah survei, pemetaan, pembuatan papan informasi, modul, sosialisasi, dan program optimalisasi wisata, selanjutnya adalah program pengurangan risiko bencana. Metode pelaksanaannya berupa program pembersihan dan penataan lingkungan desa yang dilakukan di semua dusun. Program kebersihan dan penataan desa dilakukan bersama masyarakat. Tujuan dari program ini adalah membersihkan lingkungan desa dari sampah yang dapat menyumbat drainase desa sehingga berpotensi menyebabkan banjir.

Metode pelaksanaan lainnya berupa program penghijauan desa dan pembuatan biopori. Program ini dilaksanakan bersama dengan masyarakat. Tujuan dari program ini adalah agar ada media penyerapan air permukaan sehingga mengurangi genangan air ketika terjadi hujan sehingga dapat mengurangi risiko bencana banjir. Penghijauan dan pembuatan biopori bekerja sama dengan Dinas Lingkungan Hidup. 


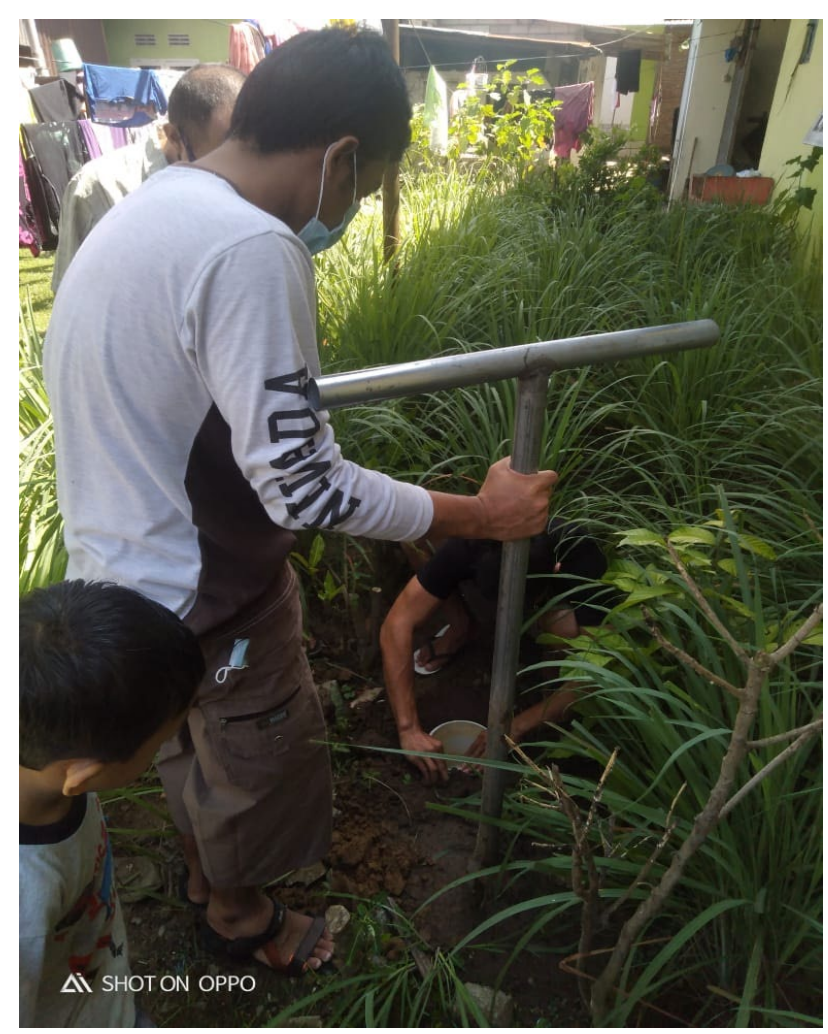

Gambar 8. Pemasangan Biopori

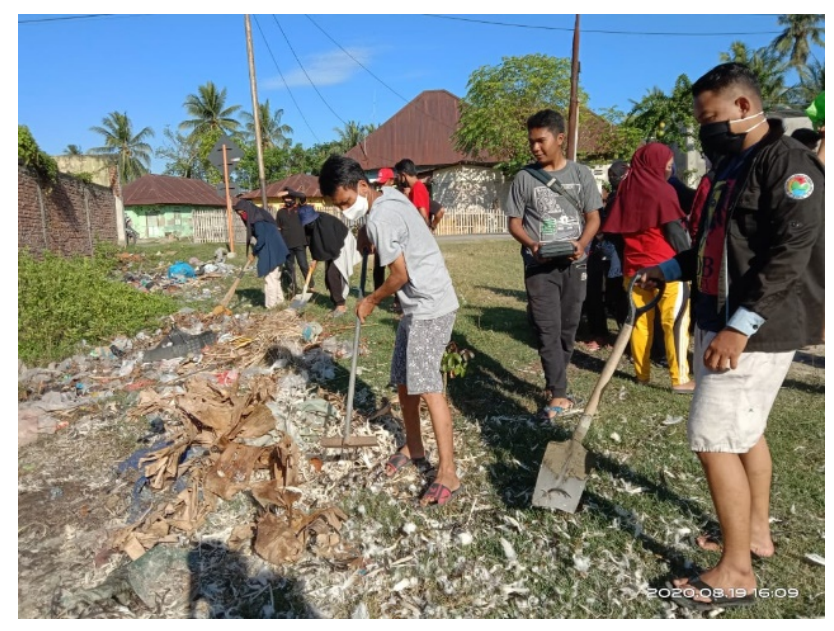

Gambar 9. Pembersihan Lingkungan Desa Bersama Masyarakat

\subsection{Pendidikan}

Setelah survei, pemetaan, pembuatan papan informasi, modul, sosialisasi, dan program optimalisasi wisata, dan program pengurangan risiko bencana, selanjutnya adalah program pendidikan. Program pendidikan berupa sekolah geotermal.

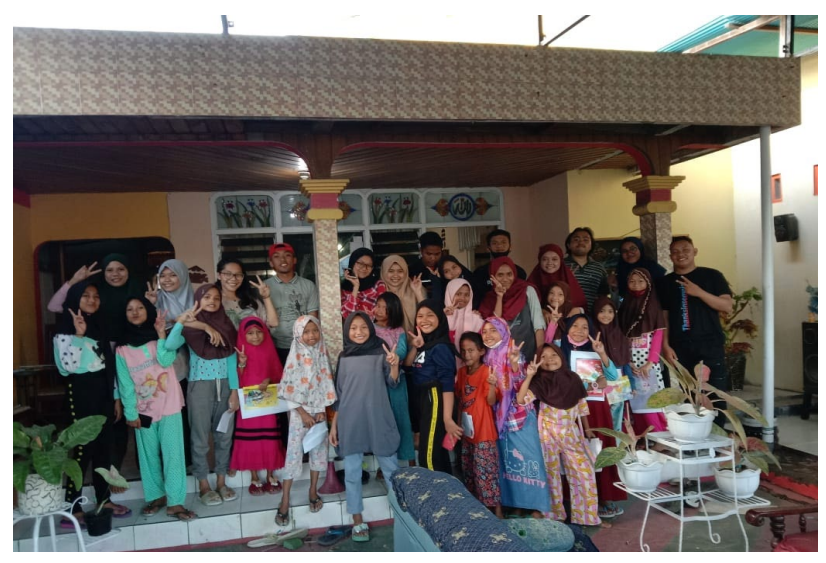

Gambar 10. Sahabat Geotermal (mahasiswa KKN Tematik Periode I tahun 2020 di Desa Pentadio Barat) bersama murid sekolah danau

Metode pelaksanaan Sekolah Geotermal berupa program pembinaan kepedulian dan kesadaran terhadap lingkungan geotermal Pentadio sejak dini bagi anak-anak SD di Desa Pentadio Barat dan program pembimbingan penulisan bagi anak-anak SD. Melalui program Sekolah Geotermal, anak-anak di Desa Pentadio Barat diharapkan akan menjadi agen perubahan masa kini dan masa depan yang akan senantiasa menjaga lingkungan geotermal serta mengembangkan potensi geotermal di Pentadio.

Luaran dari sekolah geotermal adalah buku sekolah geotermal yang ditulis oleh anak-anak SD di Desa Pentadio Barat. Sekolah geotermal akan dilanjutkan oleh karang taruna dan masyarakat desa Pentadio Barat.

\subsection{Pembuatan Media Informasi}

Setelah survei, pemetaan, pembuatan papan informasi, modul, sosialisasi, dan program optimalisasi wisata, dan program pengurangan risiko bencana, program pendidikan selanjutnya adalah pembuatan media informasi. Metode pelaksanaannya berupa program pembuatan website desa dan video KKN.

Website desa berisi profil desa, peta administrasi desa, peta situs wisata, peta situs bencana, potensi wisata dan bencana serta program-program KKN Pentadio Barat. Video KKN berisi program-program KKN. Website selanjutnya akan dikelola oleh aparat desa. 


\subsection{Program Tambahan Membersihkan Masjid}

Membersihkan masjid merupakan program tambahan yang dilakukan pada KKN Tematik Periode I tahun 2020. Adapun maksud dan tujuan diadakannya kegiatan ini adalah untuk meningkatkan kenyamanan masyarakat desa dalam beribadah dan untuk menumbuhkembangkan kepedulian terhadap pentingnya menjaga kebersihan rumah ibadah.

\subsection{Program Tambahan: Tenaga Bantu Mengajar di TPA}

Program tambahan kedua yang dilakukan pada KKN Tematik Periode I tahun 2020 adalah menjadi tenaga bantumengajar di Taman Pengajian Al Qur'an. Kegiatan ini bertujuan untuk meningkatkan kemampuan baca tulis AlQur'an dan untuk meningkatkan pengetahuan tentang ibadah bagi anak-anak di desa.

\subsection{Program Tambahan: Kegiatan Hari \\ Kemerdekaan berupa Pertunjukan \\ Kesenian dan Lomba Olahraga}

Program tambahan ketiga yang dilakukan pada KKN Tematik Periode I tahun 2020 adalah kegiatan hari kemerdekaan berupa pertunjukan kesenian dan lomba olahraga. Lomba olahraga di Desa Pentadio Barat adalah lomba lari karung, lomba ular naga, liga dangdut dan lomba tradisional khas peringatan hari kemerdekaan. Pertunjukan seni meliputi kontes kacamata dan olah vokal. Peserta KKN menerima plakat dari pemerintah desa karena telah "Mopolamahu" lipu lo Pentadio Barat pada penutupan kegiatan hari kemerdekaan dan malam puncak KKN di Desa Pentadio Barat.

\section{Kesimpulan}

\subsection{Kesimpulan}

Terlaksananya program KKN Tematik Periode I Restorasi Sungai 2020 di Desa Pentadio Barat dapat memberikan stimulus kepada pemerintah desa dan masyarakat tentang pentingnya optimalisasi wisata dan pengurangan risiko bencana. Tersedianya dokumen peta, papan informasi, modul, rancangan desa wisata dapat menjadi langkah awal untuk membuat keputusan dan mengembangkan potensi wisata serta mereduksi potensi bencana di desa. Program KKN yang menghasilkan peta administrasi, peta potensi wisata, peta potensi bencana, papan informasi wisata, papan informasi bencana, modul wisata, modul bencana, sekolah geotermal, rancangan dan rintisan wisata untuk Desa Lupoyo dan Desa Pentadio Barat dapat digunakan sebagai langkah awal dalam mewujudkan pengembangan wisata dan pengurangan risiko bencana di Desa Pentadio Barat.

\subsection{Saran}

Kolaborasi pemerintah kabupaten, dinas terkait dan universitas dengan pemerintah desa, organisasi pemuda, dan masyarakat desa dibutuhkan dalam mewujudkan desa wisata sadar bencana di Desa Pentadio Barat. Organisasi pemuda akan melanjutkan wisata sungai air panas yang selama ini belum tersentuh. Sumber daya manusia sangat dibutuhkan dalam pengembangan desa wisata yang tidak hanya menjual keindahan wisata namun juga memiliki upaya mitigasi bencana. Menjadikan Desa Pentadio Barat menjadi desa binaan merupakan salah satu peran penting universitas.

\section{Ucapan Terima Kasih}

Terlaksananya program KKN Tematik UNG dengan judul "Optimalisasi Potensi Wisata dan Pengurangan Risiko Bencana di Desa Pentadio Barat untuk Mendukung Pembangunan Berkelanjutan Daerah Dataran Danau Limboto", tidak terlepas dari partisipasi berbagai pihak. Sehingga tak lupa kami menyampaikan ucapan terima kasih dan apresiasi kepada:

a. Kementerian Pendidikan dan Kebudayaan Republik Indonesia atas dukungan dana anggaran yang telah diberikan

b. Bupati Kabupaten Gorontalo

c. Universitas Negeri Gorontalo

d. Kepala Desa Pentadio Barat

e. Serta Masyarakat Desa Pentadio Barat yang telah bersedia bekerja sama dalam menjalankan program ini.

\section{Daftar Pustaka}

[1] Andriyani, Anak Agung Istri, Edhi Martono, and Muhamad Muhamad. 2017. "Pemberdayaan Masyarakat Melalui Pengembangan Desa Wisata 
Dan Implikasinya Terhadap Ketahanan Sosial Budaya Wilayah (Studi Di Desa Wisata Penglipuran Bali)." Jurnal Ketahanan Nasional 23(1): 1.

[2] Pitana, I G. 1999. Pelangi Pariwisata Bali. Denpasar, Bali Post.

[3] Septian, Y., Ndangi, W. O. E. S., Manyoe, I. N., Taslim, I., Umar, E. P., Salama, T. H., \& Napu, S. S. (2019). Asesmen Nilai-Nilai Pariwisata Terhadap Fitur Geologi Daerah Bongo Dan Sekitarnya Sebagai Dasar Pengembangan Geowisata Di Pesisir Selatan Gorontalo. Jurnal Azimut, 2(2), 146-154.

[4] Zulfianita, and Budi Setiawan. 2015. "Pengembangan Desa Wisata Jatimalang Berbasis Industri Kreatif." ABDIMAS 19(1) 